\title{
Punctuated Equilibrium Theory and the Diffusion of Innovations
}

\author{
Graeme Boushey
}

This article builds on punctuated equilibrium theory to evaluate the diffusion of public policy innovations in the United States. The article argues that punctuated equilibrium theory provides a unifying framework for understating three mechanisms leading to the diffusion of innovations: gradual policy diffusion driven by incremental policy emulation, rapid state-to-state diffusion driven by policy imitation and mimicking, and nearly immediate policy diffusion driven by state-level responses to a common exogenous shock. Drawing upon the Bass mixed influence diffusion model, this research generates measures of the coefficients of external and internal influences for diffusion for 81 public policy innovations that have spread across the United States. The article then evaluates how the policy image and direct participation of the federal government contribute to distinct patterns of diffusion over time.

\section{Introduction}

In recent years, studies of public policy diffusion have documented considerable variation in the speed and scope of public policy adoption across states (Boushey, 2010; Makse \& Volden, 2011; Nicholson-Crotty, 2009). Although most policies spread gradually, in a manner consistent with incremental policy learning and emulation, a significant subset of innovations trigger policy outbreaks, as states across the country mimic a popular new initiative. In this regard, the process of policy diffusion produces patterns of policy change consistent with negative and positive feedback cycles familiar to punctuated equilibrium theory (PET). As Baumgartner and Jones (2009) observed, "policy diffusion, with its S-Shaped curve, is remarkably like a punctuated equilibrium model in which the system shits rapidly from one stable point to another" (p. 17).

Surprisingly, the triggers of these punctuated dynamics have been largely overlooked by extant research in public policy diffusion-the formal study of how ideas move from one jurisdiction to the next in political systems. Although researchers have suggested that policy diffusion results from decision-making processes as distinct as incremental policy emulation (Berry \& Berry, 1999; Boehmke \& Witmer, 2004; Gray, 1973; Volden, 2006; Walker, 1969), rapid policy imitation and mimicking (Boushey, 2010; Mooney \& Lee, 1999; Savage, 1985), and federal agenda setting and 
coercion (Allen, Pettus, \& Haider-Markel, 2004; Karch, 2006, 2010; Welch \& Thompson, 1980), most of this research has focused on identifying the specific mechanism of influence leading to innovation diffusion rather than distinguishing between the causes of comparative diffusion dynamics. Recent research has moved toward a more complete understanding of the factors leading to variation in the speed and scope of diffusion; however, this research has largely focused on the differences of innovation attributes (Makse \& Volden, 2011; Nicholson-Crotty, 2009) rather than broad interactions leading to policy outbreaks across state governments.

This article integrates research from punctuated equilibrium theory to distinguish between different decision-making processes leading to punctuated diffusion dynamics. Building on recent advances in the study of agenda setting and decision making (Baumgartner \& Jones, 2009; Jones \& Baumgartner, 2005; Workman, Jones, \& Jochim, 2009), the article argues that variation in the speed of innovation diffusion should be understood as resulting from the disproportionate allocation of political attention in the United States. In the majority of cases, diffusion occurs through the gradual formulation and adjustment of policy across state legislatures. At other times, state policymakers are faced with growing public demands to pass an emerging "fad" policy implemented in neighboring states. Often, new policy problems are revealed by exogenous shocks (Baumgartner \& Jones, 2009; Kingdon, 1984) or new policy solutions are demanded by the federal government (Karch, 2006). These distinct pressures systematically lead to very different temporal patterns of diffusion.

To capture the dynamic processes of innovation diffusion, this article estimates Bass (1969) mixed influence diffusion parameters for each of 81 policies that have spread across the United States. Applied to the study of public policy diffusion, the Bass mixed influence model provides a method to distinguish between the rate of policy adoption driven by state exposure to a common exogenous stimulus, such as a federal mandate or a mobilizing event, and the rate of contagion that measures policy adoption associated with endogenous influence as policies spread through interstate communication and influence. Aggregated across public policies, the Bass model provides valuable information on the standard rate of diffusion in the United States and also produces a more nuanced measure for capturing diffusion through incremental policy emulation, sudden policy mimicking, and vertical coercion.

To illustrate how Bass diffusion parameters can be applied to model the causes of punctuated dynamics in the diffusion of innovation, the article compares coefficients of external and internal influence in diffusion across a series of illustrative cases, focusing on social security policy, transportation safety, child welfare, tobacco regulation, and professional certification and licensing. These comparisons demonstrate how direct federal involvement and public responses to policies with very different attributes shape patterns of innovation diffusion. First, patterns of innovation diffusion differ drastically depending on the participation of the federal government. Direct federal intervention into state public policymaking produces R-shaped diffusion curves, consistent with exogenous influence diffusion models. Second, variation in policy attributes also shapes the speed of diffusion. Policies focusing on issues that possess broad appeal and low complexity diffuse more 
rapidly than more complex and costly regulatory policies, producing steep S-shaped cumulative diffusion curves.

\section{Policy Dynamics in Diffusion of Innovations Research}

In general, policy diffusion research has mirrored the broader study of innovation diffusion by focusing on how variation in the host, carriers, and agents interact to produce patterns of policy change in the political system (Boushey, 2010). Following Walker (1969), significant scholarly attention has focused on how variation in state political, institutional, cultural, economic, and social characteristics shapes receptivity to innovation over time (Berry \& Berry, 1990; Boushey, 2010; Canon \& Baum, 1981; Grossback, Nicholson-Crotty, \& Peterson, 2004; Nice, 1994; Savage, 1978). Researchers have demonstrated how political and institutional attributes such as state ideology (Grossback et al., 2004), legislative professionalism (Boushey, 2010; Carter \& LaPlant, 1997; Tolbert, 2002; Volden, 2006), political competition (Karch, 2006), and state public opinion (Pacheco, 2012) shape state susceptibility to innovation adoption.

Other research has identified the role of carriers in the diffusion of innovations, documenting how professional organizations (Balla, 2001; Gray, 1973; Quaile-Hill \& Hurley, 1988), interest group networks (Mintrom \& Vergari, 1998), and policy entrepreneurs (Mintrom, 1997) organize interstate efforts targeting policy change and communicate policy lessons regarding successes and failures across jurisdictions. Finally, a growing number of researchers have focused on the virulence of the idea itself and have explored how policy attributes such as cost, complexity, salience, and flexibility shape the speed and scope of innovation diffusion over time (Boushey, 2010; Makse \& Volden, 2011; Mooney \& Lee, 1999; Nicholson-Crotty, 2009; Savage, 1985).

Political scientists have also employed diffusion research to identify the mechanisms of policy influence and learning in federalism. Following the study of organizational decision making advanced by Lindblom (1959), many researchers have argued that policy diffusion results from a process of incremental learning and policy emulation by state governments (Berry \& Berry, 1990; Gray, 1973; Mooney \& Lee, 1999; Walker, 1969). By evaluating emerging innovations, state legislatures are able to reduce both the information costs and uncertainty regarding the outcomes of a new policy (Glick \& Hays, 1991; Lindblom, 1959; Volden, 2006; Weyland, 2005). This incremental learning model confirms the benefits of decentralized policymaking as states are more likely to emulate policy successes than failures (Volden, 2006).

Although incremental policy emulation through social policy learning or economic competition remains the dominant decision-making model in innovation and diffusion research, scholars have identified two important alternate mechanisms of diffusion. First, research on sudden patterns of policy adoption suggests that diffusion often occurs more rapidly than models of policy evaluation and emulation anticipate (Boushey, 2010; Lee \& Mooney, 1999; Savage, 1985). In such cases, diffusion represents a process of rapid imitation, mimicking, or isomorphic policy learning (Foucault \& Montpetit, 2011) as demands for sudden policy adoption compel deci- 
sion makers to replicate the experiments of their peers based on expected future benefits, a process May (1992) referred to as superstitious policy learning.

Other researchers have highlighted the disproportionate influence of the federal government in the vertical diffusion of innovations as state policy adoption occurs in response to the influence of the national government's agenda-setting activities. Research has identified the influence of federal mandates and grants (Allen et al., 2004; Nicholson-Crotty, 2009; Welch \& Thompson, 1980), as well as more general congressional and presidential agenda setting (Karch, 2010; McCann, Shipan, \& Volden, 2010), on state-level innovation adoption. The key distinction for these national interaction models is that diffusion occurs through vertical influence as policy-relevant information is simultaneously transferred to the many states from the federal government. ${ }^{1}$

\section{Punctuated Equilibrium and the Diffusion of Innovations}

Boushey (2010) argued that these distinct models of decision making could be integrated in a single framework. Following Baumgartner and Jones (2009), Boushey (2010) theorized that the variation in the speed and scope of diffusion resulted from the disproportionate allocation of political attention in federalism. Punctuated diffusion dynamics emerge as the policy image, receptive venues, and interest group carriers of innovation interact to produce policy change over time.

A first major implication of punctuated equilibrium theory is that political responses to innovations change with the way a problem is defined by politicians and publics. Studies in agenda setting have revealed how problem definition and issue framing alter political responses to policy problems. Shifting arguments surrounding policy reform can invite renewed interest in a policy problem, expanding the scope of conflict to new actors and eventually leading to policy change (Baumgartner \& Jones, 2009; Schattschneider, 1975). For example, the movement to regulate nuclear energy in the 1970s gained political traction when nuclear power was redefined as a potential public health and environmental threat rather than as a cheap and renewable source of energy (Baumgartner \& Jones, 2009).

Studies of policy change in American politics have documented how broad changes in the policy environment can lead to changes in the policy image (Baumgartner \& Jones, 2009; Kingdon, 1984). Sudden policy change can be triggered by a focusing event as an exogenous shock to the political system directs system-wide political attention on a new dimension of a policy problem as occurred following the Three Mile Island nuclear reactor meltdown.

Although focusing events present one source of exogenous pressure leading to policy change, such shocks are not the only mechanism leading to shifts in public policy images over time. Baumgartner and Jones (2009) observed that changes in policy indicators, as well as temporal changes in the tone of media coverage, can redirect public and political perceptions of policy problems. For example, support for tobacco regulation increased gradually as consensus emerged in the scientific community regarding the health dangers cigarettes pose to smokers and nonsmokers. 
The distinct pressures leading to shifts in political attention to specific policy problems contribute to different patterns of diffusion. Focusing events may trigger extremely rapid positive feedback cycles of policy diffusion, especially when national media coverage simultaneously focuses policymaking attention to specific policy problems across state governments. Boushey (2010) observed that when awareness of the innovation simultaneously reveals both the policy problem and the policy solution, a large number of states will simultaneously adopt the same policy innovation as decision making occurs through policy imitation rather than incremental policy emulation. However, when the image of policy reverses through a shift in policy indicators, public policy diffusion may proceed more gradually as innovation adoption is determined by shifts in local attention to an emerging problem.

Beyond the macro-political factors leading to shifts in political attention, studies of policy diffusion have further explored how the image of a particular policy innovation shapes diffusion patterns. Savage (1985) argued that rate of policy diffusion is in no small part shaped by the degree of organized opposition or "fragility" for policies targeting a particular social group. Some policy targets spur rapid political action whereas others demand less urgent responses. Child welfare policies - characterized by generally high salience, low complexity, and strong electoral support-should encourage atypically rapid patterns of diffusion (Boushey, 2010).

Other policy targets will engender less mass political involvement, resisting pressure for rapid policy change. Efforts to regulate professional groups through licensing requirements should engender considerable opposition from the targeted group but are not likely to invoke large public response. Similarly, interest group pressure may prevent rapid diffusion when a new policy reform is met with strong opposition from the entrenched policy monopoly as with efforts to enact smoking regulation (Givel, 2006).

A second key implication of punctuated equilibrium theory is that the institutional context of policymaking in the United States amplifies punctuated dynamics in the diffusion of innovations. Institutions impose decision costs that precipitate stick slip dynamics in public policymaking as pressures for policy change push against institutional rules that impose friction or gridlock on the policy process (Baumgartner et al., 2009). In this regard, the multiple veto points of policymaking in the United States should slow the process of policy diffusion as innovation adoption requires independent legislative decisions across state governments. For policy diffusion to occur at all requires significant system-wide political attention to overcome the barriers to policy change.

Although federalism makes policy coordination difficult, it also creates opportunities for considerable policy innovation, as municipal, county, and state governments develop new policies to address local concerns. Federalism encourages venue shopping, a process where activists and interest groups strategically exploit the multiple venues of government to secure support for their legislative programs (Baumgartner \& Jones, 2009; Holyoke, 2003; Pralle, 2003). This process increases the number of new ideas entering the political systems and can create conditions where "new ideas or policy images may spread rapidly across linked venues, thus setting 
in motion a positive feedback process" (Baumgartner \& Jones, 2009, p. 240). This is especially likely when a focusing event directs national political attention on a local policy reform that appeals broadly to voters. Federalism therefore creates both opportunities and constraints for rapid policy diffusion.

Baumgartner and Jones (2009) observed two different ways that issue expansion can lead to sudden patterns of policy diffusion. First, issue attention can lead to the nationalization of policy attention as federal institutions focus policymaking attention on a policy program that had previously been viewed as a concern of local and state governments. When this occurs, the federal government emerges as a strong catalyst for state-level policy adoption, employing grants, mandates, or other signals to simultaneously change policy across the states. In the 1960s, growing concern over highway conditions led to direct federal intervention in state transportation laws, most prominently linking federal highway funding to state adoption of mandatory motorcycle helmet legislation. Furthermore, Baumgartner and Jones (2009) suggested that the nationalization of issue attention on transportation safety legitimized sustained federal involvement in this issue area, resulting in a sustained period of rapid policy change.

Positive feedback cycles can also be triggered absent the direct involvement of the federal government. Boushey (2010) noted that issue attention can also be nationalized through sustained interest group campaigns as prominent advocacy groups organize to implement a policy from one state to the next. For example, state-level adoption of child abuse reporting statutes occurred not through top-down coercion but through the rapid communication of a model state law across a professional interest group network of advocacy organization (Baumgartner \& Jones, 2009).

\section{Modeling the Dynamics of Diffusion}

The competing pressures of exogenous and endogenous influence leading to policy change are well-documented in other diffusion study analogs. For example, epidemiologists have distinguished between "point source" outbreaks, which occur when a subpopulation simultaneously becomes ill after exposure to a common contaminant, and propagated person-to-person outbreaks, which emerge when a contagious disease is communicated via person-to-person interactions (Boushey, 2010; Rossman, 2012). In the social sciences, scholars in fields as diverse as communications, sociology, and marketing have distinguished between internal and external dynamics in diffusion, focusing on how mass media effects or advertising shapes the awareness of a new product or event and the extent to which consumer behavior is driven by person-to-person interactions (Bass, 1969; Rossman, Chiu, \& Mol, 2008; Valente, 1993).

These distinct diffusion processes are illustrated in three general models of diffusion. Internal diffusion models have been employed to model endogenous influence in social systems. Exogenous or external diffusion models have identified how common exogenous pressures shape adopting behavior in a social system. Integrated together, the mixed influence diffusion model captures both processes, allowing researchers to model the joint influence of exogenous and endogenous pressures on 
adoption across units in a social system. These diffusion models provide basic insights into the shape of the distribution of policy adoptions over time and provide a method for identifying innovation driven by incremental policy emulation, positive feedback cycles, and federal coercion.

\section{Internal Diffusion Models}

The internal influence diffusion model has been employed to model the contagion of a new product or innovation as it is passed from one actor to the next through interunit contact or communication. In the internal diffusion model, the mechanisms of diffusion are endogenous to the social system as diffusion results from progressive contact between units in the social system over time. This process produces what Rogers (2003) described as the diffusion curve, an S-shaped cumulative distribution curve that unfolds as an innovation spreads from a single pioneer to other actors in a social system.

Mathematically, the internal process is described by the internal influence diffusion model, given by Mahajan and Peterson (1985) as

$$
\frac{\mathrm{dN}(\mathrm{t})}{\mathrm{dt}}=\mathrm{bN}(\mathrm{t})[\overline{\mathrm{N}}-\mathrm{N}(\mathrm{t})]
$$

Where $\frac{d N(t)}{d t}$ is the rate of diffusion at time $t, N(t)$ is the cumulative number of adopters at time $\mathrm{t}, \mathrm{N}$ is the total number of potential adopters at time $\mathrm{t}$, and $\mathrm{b}$ is the constant of imitation or internal influence.

The cumulative adopters' distribution function of the internal diffusion model produces an S-shaped logistic diffusion curve, and can be represented by the following equation, given by Mahajan and Peterson (1985) as

$$
\mathrm{N}(\mathrm{t})=\frac{\overline{\mathrm{N}}}{1+\frac{\left(\overline{\mathrm{N}}-\mathrm{N}_{0}\right)}{\mathrm{N}_{0}} \exp \left[-\mathrm{b} \overline{\mathrm{N}}\left(\mathrm{t}-\mathrm{t}_{0}\right)\right]}
$$

Because the internal diffusion model provides an estimate of the constant of internal influence, the model is applied to assess the comparative contagion of distinct innovations. The constant $\mathrm{b}$ returns a measure of emulation, imitation, or contagion (Mahajan \& Peterson, 1985). A low constant b suggests innovation diffusion occurs gradually over time, while a higher value indicates more rapid unit-tounit diffusion as with imitation caused by positive feedback cycles, fads, bandwagons, or information cascades (Rossman et al., 2008). Figure 1 illustrates this dynamic with three distinct S-shaped curves representing different rates of diffusion through internal influence. The forms of these curves differ in scope and asymptote, demonstrating how changing constants of contagion can lead to differences in the rate of diffusion through a social system. ${ }^{2}$ 


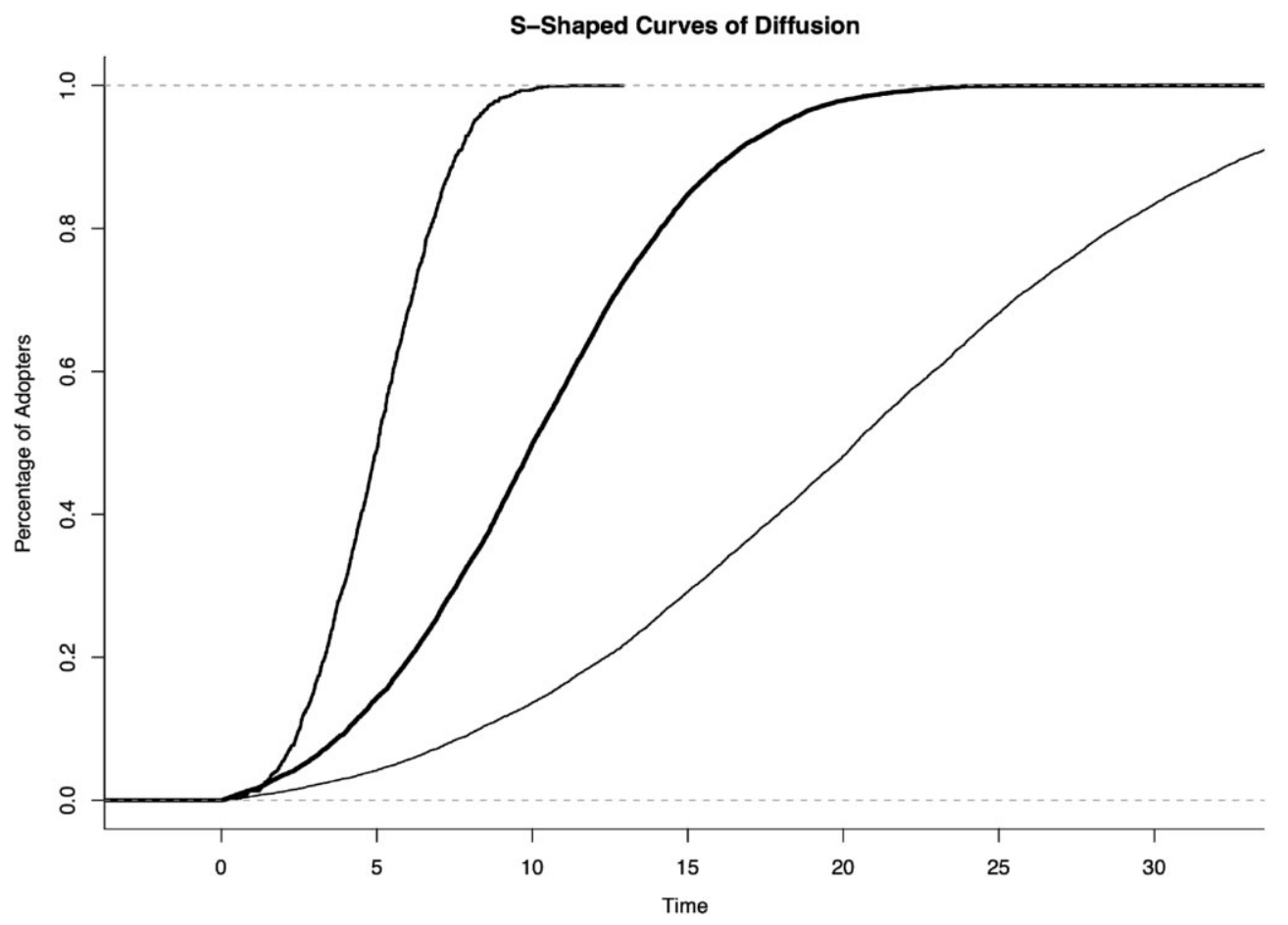

Figure 1. S-Shaped Adoption Curves.

This graph illustrates how variation in the coefficient of internal influence $b$ shapes patterns of diffusion over time. Higher values of the coefficient of internal influence produce steeper diffusion curves. Lower values of the coefficient of internal influence produce flatter diffusion curves.

\section{External Influence Models}

Diffusion through internal influence describes only one way that actors in a social system encounter innovation. In the pure external influence model of diffusion, awareness and learning about innovation occurs from pressures outside of the social system, leading a significant subset to react rapidly to an exogenous stimulus. For example, in epidemiology, sudden population exposure to environmental toxins can result in immediate and widespread illness in a very short time frame, as with the tragic Union Carbide pesticide gas leak in Bhopal, India. Plotted over time, the common source external diffusion models produce an R-shaped distribution, as the uptake of innovation may occur nearly simultaneously.

Mathematical modelers of innovation diffusion describe this process with the external influence model of innovation diffusion, given by Mahajan and Peterson (1985) as

$$
\frac{\mathrm{dN}(\mathrm{t})}{\mathrm{dt}}=\mathrm{a}[\overline{\mathrm{N}}-\mathrm{N}(\mathrm{t})]
$$


where $\frac{d N(t)}{d t}$ describes the rate of innovation adoption, $N(t)$ is the cumulative number of adopters at time $t$, and a is a coefficient or constant of external influence describing the influence of all factors other than interpersonal communication.

The cumulative density function is given by Mahajan and Peterson (1985) as

$$
\mathrm{N}(\mathrm{t})=\overline{\mathrm{N}}[1-\exp (-\mathrm{at})]
$$

Studies of innovation diffusion have employed the external diffusion model constant a to represent the influence of exogenous forces on the adoption of innovations over time. High values of a produce sharp R-shaped distributions, indicating a strong influence of the exogenous influence. Conversely, diffusion processes with lower values produce more gradual exponential curves.

\section{The Mixed Influence Diffusion Model}

The internal and external diffusion models are useful for representing theoretical diffusion processes driven by pure internal or external influence; however, both theory and observational data suggest that in most examples, social systems are jointly influenced by endogenous and exogenous forces. For example, in manufacturing, producers may wish to predict how media or advertising campaigns and word of mouth each shape the diffusion of a new product. Following the work of Bass (1969), the mixed influence diffusion model has been applied to estimate external and internal influences in the diffusion of innovations (Bass, 1969; Mahajan \& Peterson, 1985; Rossman, 2009; Srinivasan \& Mason, 1986; Valente, 1993). The Bass model returns constants of external and internal influence, allowing researchers to identify exogenous and endogenous factors contributing to the diffusion of innovations.

To model these joint processes, the mixed influence diffusion model subsumes both internal and external diffusion models into a single model, given here by Mahajan and Peterson (1985) as

$$
\frac{d N(t)}{d t}=(a+b N(t))[\bar{N}-N(t)]
$$

with a cumulative distribution function of

$$
\mathrm{N}(\mathrm{t})=\frac{\overline{\mathrm{N}}-\frac{\mathrm{a}\left(\overline{\mathrm{N}}-\mathrm{N}_{0}\right)}{\left(\mathrm{a}+\mathrm{bN}_{0}\right)} \exp \left[-(\mathrm{a}+\mathrm{b} \overline{\mathrm{N}})\left(\mathrm{t}-\mathrm{t}_{0}\right)\right]}{1+\frac{\mathrm{b}\left(\overline{\mathrm{N}}-\mathrm{N}_{0}\right)}{\left(\mathrm{a}+\mathrm{bN}_{0}\right)} \exp \left[-(\mathrm{a}+\mathrm{b} \overline{\mathrm{N}})\left(\mathrm{t}-\mathrm{t}_{0}\right)\right]}
$$

where a represents the constant of external influence, $b$ represents the coefficient of internal influence, and $\mathrm{N}$ represents the total number of units adopting the innovation.

It is important to note that the mixed influence model retains features of the internal and external diffusion models. When the constant a reduces to zero, the Bass 


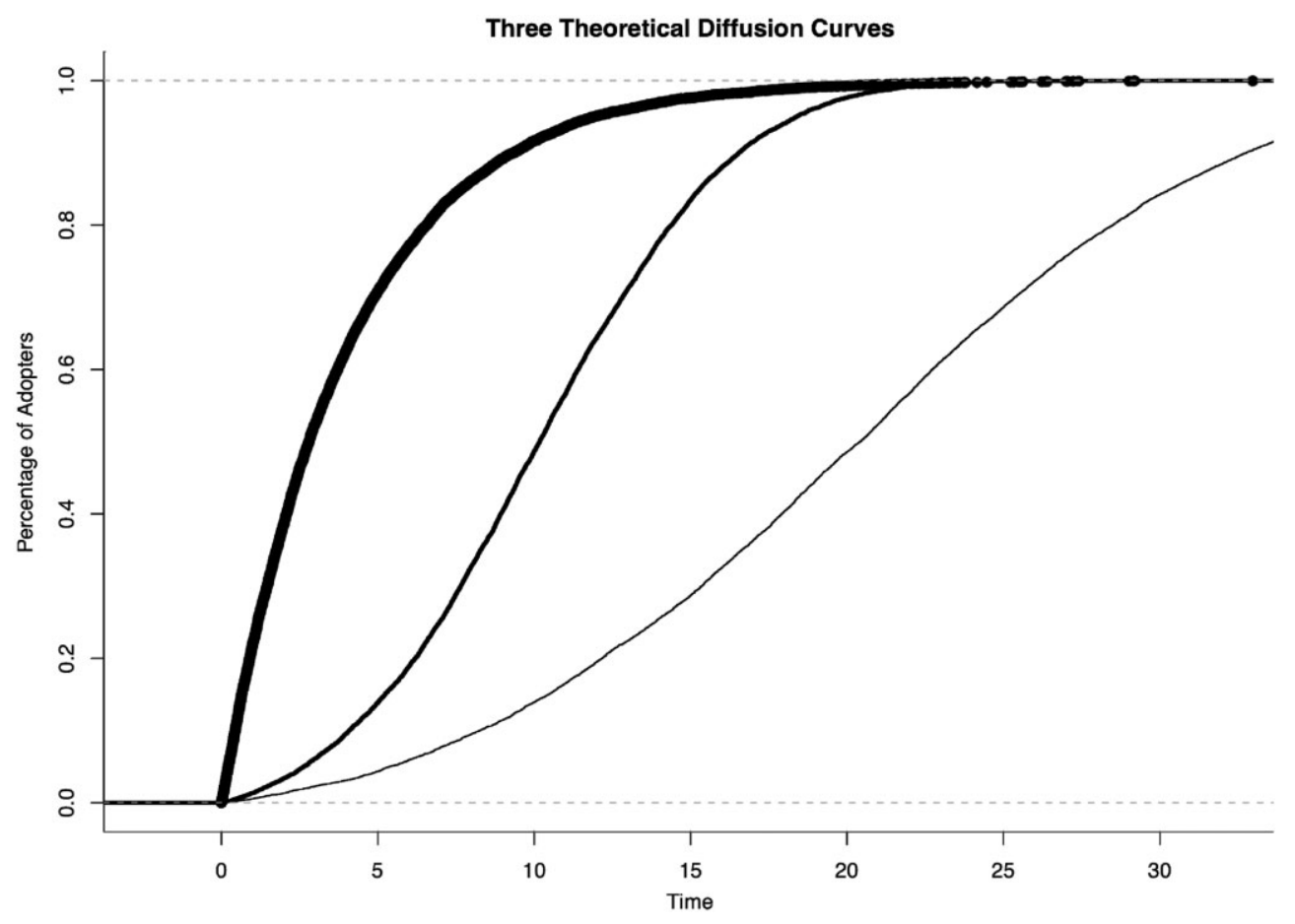

Figure 2. Theoretical Diffusion Curves.

This graph illustrates how variation in the coefficients of external and internal influence shapes patterns of diffusion over time. Higher values of the coefficient of internal influence produce steeper diffusion curves. Lower values of the coefficient of internal influence produce flatter diffusion curves.

mixed influence model represents a logistic diffusion function and essentially becomes an internal influence or contagion model (Chandrasekaran \& Tellis, 2008). When constant $b$ equals zero, the model reduces to an exponential function representing pure exogenous influence on the diffusion of innovations. Positive values for both parameters represent the joint influence that exogenous and endogenous contagions have on diffusion of innovation.

Figure 2 illustrates three different rates of innovation diffusion curves resulting from the Bass mixed influence diffusion model. Innovations with high coefficients a will return diffusion curves similar to the external influence model. Innovations with high coefficients $b$ will return more gradual S-shaped curves characteristic of the internal diffusion model. Innovations with joint influence fall in between these two theoretical curves depending on the size of the constants of external and internal influence.

\section{Mixed Influence Models and Punctuated Equilibrium Theory}

The mixed influence diffusion model provides a powerful tool for modeling the dynamic processes of innovation diffusion driven by incremental policy emulation and sudden positive feedback cycles resulting from either federal coercion or sudden 
policy mimicking. ${ }^{3}$ The coefficient of external influence a captures the extent to which a subset of state governments are responding to exogenous agenda setting pressures, such as those resulting from a focusing event or federal mandates. The mixed model's internal influence constant $b$ provides the contagion parameter, allowing researchers to distinguish between rapid policy diffusion characteristic of positive feedback cycles, policy outbreaks, and fads, and more gradual policy diffusion consistent with incremental emulation. A higher value of the constant $b$ indicates a faster rate of diffusion, implying policy diffusion through positive feedback cycles rather than gradual incremental emulation. ${ }^{4}$

\section{Data and Method}

The cases selected for analysis parallel those examined in Agendas and Instability in American Politics (Baumgartner \& Jones, 2009). This approach allows us to understand how processes leading to national level policy change also shaped individual patterns of diffusion. The research relies on these cases to illustrate how federal mandates, mobilizing events, changes in policy indicators, shifts in policy targets, and differences in issue complexity have historically triggered different patterns of diffusion.

To evaluate patterns of policy diffusion in the United States, this investigation gathered information on state years of adoptions for 81 different innovations. Following Walker's definition of innovation as "a program or policy which is new to the state adopting it, no matter how old the program may be or how many other states have adopted it" (1969, p. 881), the study only included innovations that were formally enacted into law by state governmental institutions. Furthermore, following prior research that restricted innovations by the scope of diffusion, this research instead restricted the sample to innovations adopted by at least 10 states prior to $2009^{5}$ (Canon \& Baum, 1981; Savage, 1978; Walker, 1969).

Because of the considerable difficulties identifying the universe of policy innovations, this research followed a convenience sampling strategy, drawing heavily from prior published research in public policy diffusion. The data set includes policies drawn from Walker's (1969), Boushey's (2010), and Makse and Volden's (2011) large data sets, as well as a number of individual cases identified through key word searches in JSTOR and Expanded Academic Index. These data span issue areas representing welfare, health and public safety, crime and corrections, taxes, licensing and professional regulation, education, elections, sexuality, state economic development, and environmental policy. However, policies are not evenly distributed across issue areas as the data set includes a significant oversample of contemporary criminal justice policies. ${ }^{6}$ A full list of these policies, as well as supplementary files for replication, are available from the author. ${ }^{7}$

Policies were coded along two dimensions. First, innovations were sorted by issue area, specifically identifying child welfare, transportation safety, smoking regulation, criminal justice, and professional licensing policies. Issues were classified as child welfare policy when the innovation directly addressed the welfare or wellbeing of children. ${ }^{8}$ Transportation safety measures included policies protecting drivers, passengers, and bike riders. ${ }^{9}$ Licensing policies represent public policies that 
specifically grant entry to and maintain professional standards for the conduct and practice of specialized labor in the states. Finally, tobacco regulation policies included all efforts to regulate consumption of and access to tobacco. All remaining policies that did not fall into these categories were coded into a common reference group.

Researchers also coded policies by federal intervention, identifying whether each innovation had been the focus of a major federal mandate or grant-in-aid program. Because of the difficult challenges of matching 81 policies spanning a century to information on supplementary federal grant programs and policy recommendations, this research adopted an extremely conservative coding scheme that counted only programs initiated through major federal grants and/or mandates. ${ }^{10}$

To construct the dependent variables for analysis, this study employed nonlinear least squares regression (NLS) to estimate Bass mixed influence diffusion parameters of internal and external influence for each policy innovation (Srinivasan \& Mason, 1986). ${ }^{11}$ NLS methods have been shown to produce less biased estimates of the Bass diffusion parameters than prior methods using ordinary least squares (OLS) or maximum likelihood estimation (MLE) (Srinivasan \& Mason, 1986). The approach provides estimates and standard errors for the coefficients $\mathrm{a}, \mathrm{b}$, and $\mathrm{N}$ for each policy innovation under analysis. ${ }^{12}$ Replication code and a procedure for producing Bass estimates on a sample data set are available from the author (see note 7). Finally, this study employed analysis variance and comparison of means tests to evaluate mean differences in the rates of diffusion across these issue areas.

\section{Results}

This research first calculated the mean values for the coefficients of external and internal influence in public policy diffusion across the full sample of 81 innovations. ${ }^{13}$ Larger values of the coefficient of external influence $(a>0.10)$ are associated with sharp exponential diffusion curves, indicating a strong influence of external factors on the diffusion of policy innovations. Smaller values of the constant $b$ are associated with gradual S-shaped cumulative diffusion curves over time, while higher values produce steep S-shaped curves. Table 1 presents mean values for the overall sample, as well as Bass diffusion estimates for four illustrative cases-the diffusion of mandatory motorcycle helmet legislation, the Amber Alert, charter school legislation, and restaurant smoking bans.

As predicted by the general punctuation hypothesis, Table 1 documents considerable variation in rates of diffusion in the overall sample, suggesting that the friction imposed by the institution of federalism generally leads to disjointed patterns of diffusion. The average value for the coefficient of external influence a is $0.02(\mathrm{~min}=0$, $\max =0.31$, standard deviation $[S D]=0.05$.) The mean value for the coefficient of internal influence $\mathrm{b}$ is 1.03 ( $\mathrm{min}=0.03$, maximum $=4.75, \mathrm{SD}=1.07)$. This research therefore identifies considerable variation in the rates of exogenous and internal diffusion consistent with broader research on distributions of policy change in PET.

To illustrate how Bass diffusion can be used to distinguish between diffusion triggered by incremental policy emulation, positive feedback cycles, and federal intervention, Table 1 highlights Bass diffusion coefficients for a subset of 
Table 1. Bass Mixed Model Estimates for Rates of Innovation Diffusion

\begin{tabular}{lccc}
\hline \multirow{2}{*}{ Policy } & \multicolumn{3}{c}{ Diffusion Model Parameters } \\
\cline { 2 - 4 } & $\mathrm{N}$ & $\mathrm{a}$ & $\mathrm{b}$ \\
\hline All policies & 42 & 0.22 & 1.03 \\
Mandatory motorcycle & $52.557^{*}$ & $0.314^{*}$ & $0.957^{*}$ \\
$\quad$ helmet, 1967-85 & 3.160 & 0.063 & 0.227 \\
Amber Alert, 1999-2006 & $47.570^{*}$ & 0.000 & $3.012^{*}$ \\
Charter schools enabling & 1.681 & 0.000 & 0.305 \\
$\quad 39.284^{*}$ & $0.018^{*}$ & $0.625^{*}$ \\
legislation, 1991-2004 & 5.508 & 0.010 & 0.132 \\
Restaurant smoking ban, & $37.299^{*}$ & 0.014 & 0.192 \\
1981-2000 & 12.396 & 0.012 & 0.118 \\
\hline Standard errors in italics & & & \\
${ }^{*} p<0.05$. & & &
\end{tabular}

representative cases. As expected, motorcycle helmet legislation is characterized by an extremely high coefficient of external influence and an average constant of internal influence $(a=0.31, b=0.957)$, while the Amber Alert is marked by a very small value of external influence and a high coefficient of internal influence $(a=0$, $\mathrm{b}=3.02$.) Restaurants smoking bans have lower than average coefficients of internal and external diffusion, indicative of policy incrementalism $(a=0.01, b=0.19) .{ }^{14}$ Finally, the diffusion of state charter school legislation provides a reference illustrating the average values for both external $(\mathrm{a}=0.02)$ and internal influence $(b=0.63)$ in diffusion.

Figure 3 plots the empirical and predicted Bass distinct diffusion curves for these four representative innovations. Here, the diffusion of motorcycle helmet legislation shows the steep R-shaped curve indicative of exogenous influence diffusion common in federal interaction models. The Amber Alert has a steep S-shaped diffusion curve indicative of a positive feedback cycle. State adoption of charter schools legislation follows the classic S-shaped diffusion curve most closely, representative of a process of incremental policy emulation. Restaurant smoking adoptions produce a more extreme diffusion curve of incremental policy emulation as the innovation spread more slowly in response to evolving preferences for tobacco legislation across the 50 states.

These graphs stand as a reference for understanding how variation in Bass diffusion parameters related to patterns of diffusion over time. High values for the constant of external influence a produce R-shaped exponential diffusion curves as with the mandatory motorcycle helmet legislation. High values for the constant $b$ produce steep S-shaped distributions similar to the Amber Alert. Lower values for both parameters produce more gradual S-shaped distributions, indicating gradual policy diffusion, as with charter schools or indoor smoking regulation.

Table 2 produces average values for internal and external influence in diffusion across transportation safety policy, child welfare policy, professional licensing policy, and smoking regulation. Table 2 also considers the rates of diffusion for a small group of policies initiated by the federal government through major grants or 
Mandatory Motorcycle Helmet Laws

\section{Amber Alert}
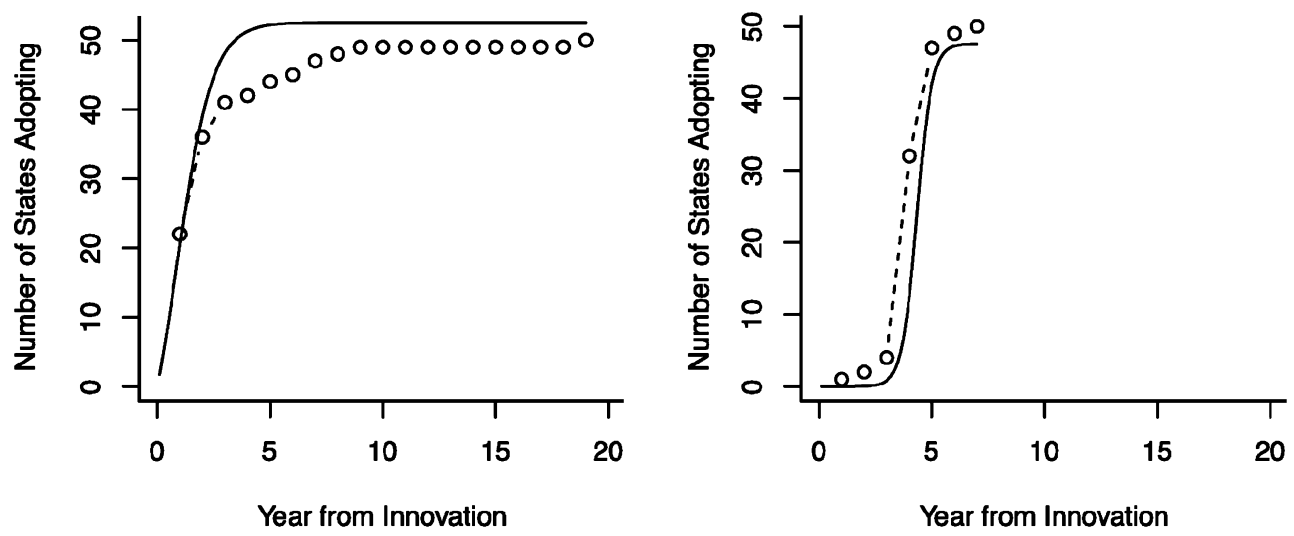

\section{Charter Schools Legislation}
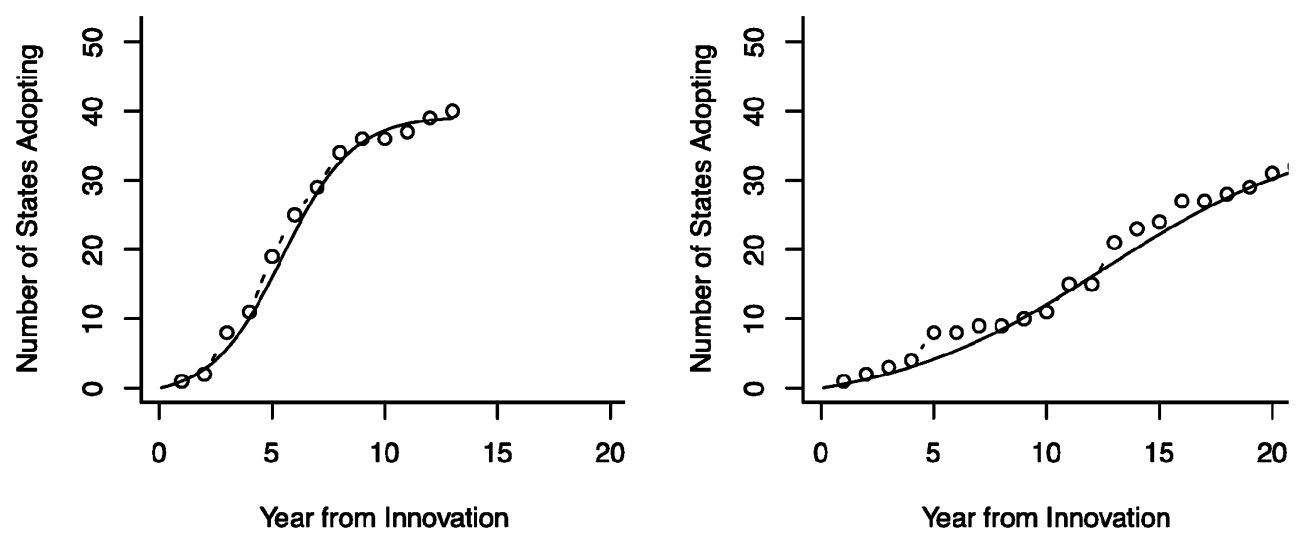

Figure 3. Empirical and Bass Diffusion Curves for Distinct Cases of Innovation Diffusion. The dashed and dotted line represents the empirical cumulative number of adoptions over time. The solid line represents the Bass diffusion estimates for the cumulative number of adoptions over time.

mandates. These comparisons across samples provide for a preliminary test of the hypothesis that punctuated dynamics are in part shaped by systematic pressures related to both external and internal diffusion models.

Perhaps the more interesting findings emerge in the comparison of the triggers of punctuated diffusion dynamics in the United States. The three policies that spread through direct federal intervention (mandatory motorcycle helmet legislation, aid for families with dependent children, and aid to the disabled) produced average external influence diffusion parameters of $b=0.24$, a statistically significant difference from the overall population average of $0.02\left(\chi^{2}=8.5, p<0.05\right)$. Although the small sample and limitations in classifying federal intervention mean this result should be read with caution, the finding nonetheless lends preliminary support the general claim that the nationalization of issue attention leading to direct federal 
Table 2. Bass Model Estimates for Policies Grouped by Issue Area

\begin{tabular}{lrccccc}
\hline & N & $\begin{array}{c}\text { External } \\
\text { Influence (a) }\end{array}$ & $\begin{array}{c}\text { Internal } \\
\text { Influence (b) }\end{array}$ & SD & Min & Max \\
\hline All policies & 81 & 0.02 & & 0.05 & 0.00 & 0.31 \\
Federal mandates & 3 & 0.24 & & 0.07 & 0.19 & 0.31 \\
Transportation safety & 4 & 0.09 & & 0.15 & 0.01 & 0.31 \\
Child welfare & 8 & 0.03 & & 0.07 & 0.00 & 0.21 \\
Professional licensing & 5 & 0.01 & & 0.01 & 0.00 & 0.03 \\
Smoking regulation & 3 & 0.007 & 1.03 & 0.007 & 0.00 & 0.014 \\
All policies & 81 & & 1.42 & 0.44 & 0.03 & 4.75 \\
Federal mandates & 3 & & 1.26 & 0.43 & 0.84 & 1.82 \\
Transportation safety & 4 & & $1.28 \mathrm{~s}$ & 0.99 & 0.27 & 3.72 \\
Child welfare & 8 & & 0.27 & 0.05 & 0.20 & 0.32 \\
Professional licensing & 5 & & 0.345 & 0.188 & 0.192 & 0.54 \\
Smoking regulation & 3 & & & & & \\
\hline
\end{tabular}

intervention can fundamentally change the process of innovation diffusion. When policy attention is nationalized and the federal government intervenes strongly in state affairs, rapid diffusion will resemble an external influence diffusion process.

Table 2 also provides an initial test of the factors contributing to variation in the coefficient of internal influence across issue areas. Following prior research in policy diffusion and punctuated dynamics in policymaking, this research anticipated that smoking regulation and professional licensing policy would both produce gradual diffusion curves while both child protection and transportation safety policy would be more likely to trigger positive feedback cycles.

The three tobacco regulatory policies in the sample (regulating smoking in restaurants, government buildings, and the sale of out-of-package cigarettes) have an average rate of 0.35 for the constant of internal influence. This falls well below the mean value of diffusion, suggesting tobacco policy may be slowed by the participation of organized interests, coupled with cautious state emulation of regulatory policies. The research also confirms the low coefficient of imitation for professional licensing policies $(b=0.27)$, confirming a finding of Boushey (2010) that professional regulatory policy would be characterized by incremental decision making.

A different dynamic emerges in the rapid diffusion of child welfare policies. These policies have average coefficients of external influence $(a=0.03)$, but higher than average values of internal influence $(b=1.30)$, suggesting these child welfare standard policy innovations spread more rapidly than standard policy innovations. Transportation safety policy is also characterized by high values of both external and internal influence $(a=0.09, b=1.26)$, although the value of the external influence coefficient reduces to the mean value of 0.02 when motorcycle helmet policy is excluded. This provides very preliminary support that diffusion occurs more rapidly following the nationalization of issue attention within a policy area.

Although the Kruskal-Wallis rank sum test confirms no statistically significant difference between the values of external or internal influence across these policy types, there is some support that the speed of internal diffusion is shaped by 
the policy characteristic. The comparison of these subgroup means is suggestive, given the limited sample of policies falling within these four groups $\left(\chi^{2}=6.38\right.$, $p<0.10)$.

\section{Conclusion}

The findings presented in this article align policy diffusion with recent research in political decision making and punctuated equilibrium theory (Baumgartner \& Jones, 2009; Boushey, 2010; Jones \& Baumgartner, 2005). The considerable variation in the speed and scope of diffusion can be explained by the disproportionate allocation of political attention across policymaking institutions in federalism. As a general rule, policymakers are constrained by a scarcity of time, resources, and political attention. When policy attention to a specific issue area is limited, patterns of incremental policy emulation unfold gradually as decision makers update policy with "successive limited comparison" of regional alternatives (Lindblom, 1959). However, when policymaking attention is focused squarely on a specific issue area, policy change across the 50 states can occur rapidly as political institutions rush to respond to a new component of a policy threat.

This interaction of policy image and institutional venue is central for understanding policy diffusion dynamics. When issues traditionally left to the state and local governments are nationalized, policy diffusion can occur extremely rapidly as the federal government mandates innovation adoption across the country. When a focusing event captures state-level attention, diffusion may trigger a policy bandwagon as states rapidly imitate the innovations of their peers. This research suggests that historically, certain issues are more likely to precipitate sudden patterns of policy change. For example, child welfare policy (a policy area with high salience and broad public support) will generally diffuse more rapidly than professional licensing policy, which engenders little public attention.

The Bass diffusion model provides empirical leverage for distinguishing between the distinct pressures that lead to policy diffusion in the United States. The Bass model provides estimates for both internal and external diffusion, allowing researchers to distinguish between incremental policy emulation, sudden policy feedback cycles, and sudden policy change in response to exogenous shocks. In this regard, Bass diffusion model improves upon prior research in policy diffusion that employed simple dichotomous measures of rate to distinguish between rapid and slow diffusion (Nicholson-Crotty, 2009). This is an important distinction as sudden policy change resulting from policy mimicking and state responses to federal coercion result from distinct decision-making processes. Across issue areas, the Bass model provides a simple method for interpreting these pressures leading to variation in the rate of diffusion.

Future research should employ Bass diffusion estimates to expand on the role of policy indicators and mobilizing events in policy diffusion. The study of policy diffusion has too often ignored the process of problem definition leading to policy change, choosing instead to identify how the attributes of states or the complexity of the innovation relate to patterns of diffusion. Our understanding of the policy 
process leading to the diffusion of innovations will be richer if research more clearly identifies how changes in policy images precipitate the diffusion of innovations.

Graeme Boushey is a Robert Wood Johnson Scholar in Health Policy Research at the University of Michigan and an assistant professor at the University of California, Irvine.

\section{Notes}

The author wishes to thank Bryan Jones, Gabriel Rossman, Christophe Van den Bulte, David Klein Jones, Jared Green, and the editors of Policy Studies Journal Peter deLeon and Chris Weible for their valuable feedback and comments on this research. Any errors and omissions that remain are entirely my own.

1. Vertical diffusion models have also documented the process of bottom-up diffusion, as local initiatives influence the policy choices of state and national governments over time (see Shipan \& Volden, 2006).

2. Virginia Gray (1973) employed a form of this internal diffusion model to evaluate cumulative adoption curves in her classic article "Innovation in the States: A Diffusion Study."

3. Surprisingly, although characteristics of U.S. policy diffusion data make it especially suitable for Bass analysis (Mahajan \& Peterson, 1985), the mixed-influence diffusion model has been largely overlooked in political science (exception: Mahajan, Haynes, \& Kumar, 1977).

4. In addition to providing a technique for differentiating between endogenous and exogenous policy punctuations in innovation diffusion, the mixed influence provides a second important corollary to methods familiar to students of PET. The mixed influence diffusion model provides estimates based on the analysis of the distribution of policy adoptions over time. The Bass model estimates the degree to which innovation diffusion represents a pure logistic distribution, an exponential distribution, or a mixture of the two. The Bass model therefore provides an appropriate method for assessing policy punctuations and positive feedback cycles in diffusion data as the underlying processes are virtually identical to the dynamics identified in the empirical models advanced in PET theory.

5. Prior research set a higher threshold for identifying cases of diffusion, generally including only policies that had been adopted by at least 20 states over the time period.

6. This oversample results from the disproportionate number of crime policies collected from Makse and Volden's (2011) and Boushey's (2010) data sets. A comparison of means tests across rates of diffusion for criminal justice and other policies suggests little difference between the measures of diffusion.

7. Data and replication files can be accessed at http://sitemaker.umich.edu/gboushey.

8. Innovations that indirectly address child welfare (such as teacher certification policies or charter schools enabling legislation) were not included in this category.

9. Both bike helmet and child seat belt legislation could be considered both child welfare and transportation safety policy. In this case, these policies were counted as transportation safety policies. Classifying these policies as child welfare innovations did little to alter the substantive findings in this article.

10. This conservative classification scheme almost certainly underestimates the role of the federal government in promoting policy diffusion. Future research should measure how differences in the instruments employed by the federal government (mandates, categorical grants in aid, competitive grants, or policy recommendations) shape patterns of diffusion.

11. Nonlinear least squares regression (NLS) models are extremely sensitive to start values for N, a, and b. To identify plausible start values, this research used an Excel Bass diffusion template that estimates diffusion parameters based on the cumulative number of policy adoptions over time. This approach provided for a reliability check on the final estimates. The values reported in the article were estimated based on the total number of adoptions per time period, which produces more reliable estimates of the Bass parameters.

12. NLS produces Bass diffusion coefficients through curve fitting. However, this procedure is extremely sensitive to start values. For a large subset of policies excluded from this analysis, this method could not produce diffusion parameters. An analysis of these cases suggests that the model failed to produce estimates when there was a considerable lag between periods of adoption. As a result, this method 
understates the disjointed and episodic nature of diffusion, as only policies with relatively short intervals between state policy adoptions were included.

13. The estimates for $a$ and $b$ produced by the Bass model are not directly comparable with each other. Values for the coefficient of external influence a can range between 0 and 1, while values for internal influence $b$ can take a broader range of policy values.

14. Students of punctuated equilibrium theory may also be interested to note that the W statistic indicates that rapid diffusion processes deviate from the normal distribution, providing another check of incrementalism in diffusion.

\section{References}

Allen, Mahalley, Carrie Pettus, and Donald Haider-Markel. 2004. "Making the National Local: Specifying the Conditions for National Government Influence on State Policymaking." State Politics and Policy Quarterly 4: 318-44.

Balla, Steven J. 2001. "Interstate Professional Associations and the Diffusion of Policy Innovations." American Politics Research 29 (3): 221-45.

Bass, Frank M. 1969. “A New Product Growth Model for Consumer Durables.” Management Science 15: 215-27.

Baumgartner, Frank, and Bryan Jones. 2009. Agendas and Instability in American Politics. Chicago: University of Chicago Press.

Baumgartner, Frank, Christian Breunig, Christoffer Green-Pedersen, Bryan D. Jones, Peter B. Mortensen, Michiel Neytemans, and Stefaan Walgrave. 2009. "Punctuated Equilibrium in Comparative Perspective." American Journal of Political Science 53 (3): 602-19.

Berry, Frances S., and William D. Berry. 1990. "State Lottery Adoptions as Policy Innovations: An Event History Analysis." American Political Science Review 84 (2): 395-415.

. 1999. "Innovation and Diffusion Models in Policy Research." In Theories of the Policy Process, ed. Paul A. Sabatier. Boulder, CO: Westview Press, 169-200.

Boehmke, Frederick J., and Richard Witmer. 2004. “Disentangling Diffusion: The Effects of Social Learning and Economic Competition on State Policy Innovation and Expansion." Political Research Quarterly 57 (1): 39-51.

Boushey, Graeme. 2010. Policy Diffusion Dynamics in America. Cambridge: Cambridge University Press.

Canon, Bradley C., and Lawrence Baum. 1981. "Patterns of Adoption of Tort Law Innovations: An Application of Diffusion Theory to Judicial Doctrines." American Political Science Review 75 (4): 975-87.

Carter, Larry, and James LaPlant. 1997. "Diffusion of Health Care Policy Innovation in the United States." State and Local Government Review 29: 17-26.

Chandrasekaran, Deepa, and Gerard J. Tellis. 2008. "A Critical Review of Marketing Research on Diffusion of New Products." In Review of Marketing Research, Vol. 3, ed. Naresh K. Malhotra. Armonk, NY: M.E. Sharpe, 39-80.

Foucault, Martial, and Eric Montpetit. 2011. "Diffusion of Policy Attention in Canada: Evidence from Speeches from the Throne, 1960-2008." In Agenda-Setting from a Policy Theory to a Theory of Politics, ed. Christopher Green-Pedersen, and Stefaan Walgrave. Chicago: Chicago University Press, Forthcoming.

Givel, Michael. 2006. "Punctuated Equilibrium in Limbo: The Tobacco Lobby and U.S. State Policy-Making From 1990 to 2003." Policy Studies Journal 43 (3): 405-18.

Glick, Henry R., and Scott P. Hays. 1991. "Innovation and Reinvention in State Policymaking: Theory and the Evolution of Living Will Laws." Journal of Politics 53 (3): 835-50.

Gray, Virginia. 1973. "Innovation in the States: A Diffusion Study." American Political Science Review 67 (4): 1174-85.

Grossback, Lawrence J., Sean Nicholson-Crotty, and David A. Peterson. 2004. "Ideology and Learning in Policy Diffusion." American Politics Research 32 (5): 521-45. 
Holyoke, Thomas T. 2003. "Choosing Battlegrounds: Interest Group Lobbying across Multiple Venues." Political Research Quarterly 56: 325-36.

Jones, Bryan, and Frank Baumgartner. 2005. The Politics of Attention: How Government Prioritizes Problems. Chicago: University of Chicago Press.

Karch, Andrew. 2006. "National Intervention and the Diffusion of Policy Innovations." American Politics Research 34 (4): 403-26.

_ 2010. "Vertical Diffusion and the Policymaking Process: The Politics of Embryonic Stem Cell Research." Political Research Quarterly, doi: 10.1177/1065912910385252.

Kingdon, John. 1984. Agendas, Alternatives, and Public Policies. Boston: Little, Brown.

Lee, Mei-Hsien, and Christopher Z. Mooney. 1999. "The Temporal Diffusion of Morality Policy: The Case of Death Penalty Legislation in the American States." Policy Studies Journal 27 (4): 766-80.

Lindblom, Charles E. 1959. “The Science of 'Muddling Through'." Public Administration Review 19: 79-88.

Mahajan, Vijay, and Robert A. Peterson. 1985. Models for Innovation Diffusion. Thousand Oaks, CA: Sage.

Mahajan, Vijay, Kingsley E. Haynes, and Bal Kumar. 1977. "Modeling the Diffusion of Public Policy Innovations in the United States." Socio-Economic Planning Sciences 11 (5): 259-63.

Makse, Todd, and Craig Volden. 2011. "The Role of Policy Attributes in the Diffusion of Innovations." Journal of Politics 73 (1): 108-12.

May, Peter. 1992. "Policy Learning and Failure." Journal of Public Policy 12 (4): 331-54.

McCann, Pamela, Charles Shipan, and Craig Volden. 2010. “Intergovernmental Policy Diffusion: National Influence on State Policy Adoptions." Paper presented at the Annual Midwest Political Science Association Conference, April 22-25, Chicago, IL.

Mintrom, Michael. 1997. "Policy Entrepreneurs and the Diffusion of Innovation." American Journal of Political Science 41 (3): 738-70.

Mintrom, Michael, and Sandra Vergari. 1998. "Policy Networks and Innovation Diffusion: The Case of State Education Reforms." Journal of Politics 60 (1): 126-48.

Mooney, Christopher, and Mei-Hsien Lee. 1999. "Morality Policy Reinvention: State Death Penalties." The Annals of the American Academy of Political and Social Science 566 (1): 80-92.

Nice, David C. 1994. Policy Innovation in State Government. Ames, IA: Iowa State University Press.

Nicholson-Crotty, Sean. 2009. “The Politics of Diffusion: Public Policy in the American States." Journal of Politics 71 (1): 192-205.

Pacheco, Julianna. 2012. "The Social Contagion Model: Exploring the Role of Public Opinion on the Diffusion of Anti-Smoking Legislation across the American States." To appear in Journal of Politics.

Pralle, Sarah. 2003. "Venue Shopping, Political Strategy, and Policy Change: A Case Study of Canadian Forest Advocacy." Journal of Public Policy 23: 233-60.

Quaile-Hill, Kim, and Patricia A. Hurley. 1988. “Uniform State Law Adoptions in the American States: An Explanatory Analysis." Publius: The Journal of Federalism 18 (1): 117-26.

Rogers, Everett M. 2003. Diffusion of Innovations, 5th ed. New York: Free Press.

Rossman, Gabriel. 2009. "The Diffusion of the Legitimate and the Diffusion of Legitimacy." California Center for Population Research On-Line Working Paper Series. University of California, Los Angeles. 2012. Climbing the Charts. Princeton, NJ: Princeton University Press.

Rossman, Gabriel, Ming Ming Chiu, and Joeri Mol. 2008. “Modeling Diffusion of Multiple Innovations via Multilevel Diffusion Curves: Payola in Pop Music Radio." Sociological Methodology 38: 201-30.

Savage, Robert. 1978. "Policy Innovativeness as a Trait of American States." Journal of Politics 40 (1): $212-24$. . 1985. "When a Policy's Time Has Come: Cases of Rapid Policy Diffusion 1983-1984." Publius 15 (3): 111-26.

Schattschneider, Elmer E. 1975. The Semi-Sovereign People. Hinsdale, IL: Dryden Press.

Shipan, Charles R., and Craig Volden. 2006. "Bottom-Up Federalism: The Diffusion of Antismoking Policies from U.S. Cities to States." American Journal of Political Science 50 (4): 825-43.

- 2008. "The Mechanisms of Policy Diffusion." American Journal of Political Science 52 (4): 840-57. 
Srinivasan, V. Seenu, and Charlotte H. Mason. 1986. "Nonlinear Least Squares Estimation of New Product Diffusion Models." Marketing Science 5 (2): 169-78.

Tolbert, Caroline. 2002. "Rethinking Lowi's Constituent Policy: Governance Policy and Direct Democracy." Environment and Planning C: Government and Policy 20 (1): 75-93.

Valente, Thomas. 1993. "Diffusion of Innovations and Policy Decision-Making." Journal of Communication 43 (1): 30-45.

Volden, Craig. 2006. "States as Policy Laboratories: Emulating Success in the Children's Health Insurance Program." American Journal of Political Science 50 (2): 294-312.

Walker, Jack L. 1969. "The Diffusion of Innovation among the American States." American Political Science Review 63 (3): 880-89.

Welch, Susan, and Kay Thompson. 1980. "The Impact of Federal Incentives on State Policy Innovation." American Journal of Political Science 24 (4): 715-29.

Weyland, Kurt. 2005. “Theories of Policy Diffusion." World Politics 57: 262-95.

Workman, Samuel, Bryan D. Jones, and Ashley E. Jochim. 2009. "Information Processing and Policy Dynamics." Policy Studies Journal 37 (1): 75-92. 